\title{
captación de aguas subălveas en la confluencia de los ríos Lozoya y Jarama
}

EMILIO LOPEZ DE BERGES Y DE LOS SANTOS, Dr. ingeniero de caminos, canales y puertos

sinopsis

$536 \cdot 11$

El objeto del dispositivo que se describe es aprovechar el caudal subálveo de la confluencia de los ríos Lozoya y Jarama, para incorporarlo al abastecimiento de agua a Madrid.

La captación se realiza con dos pozos Ranney, con drenes radiales de palastro ranurados longitudinalmente y con una longitud total de unos $500 \mathrm{~m}$ para cada pozo.

El agua filtrada es impulsada al Canal de La Parra por una tubería de acero electrosoldada con capacidad de $1 \mathrm{~m}^{3} / \mathrm{s}$.

Para aumentar la carga de agua sobre los drenes se ha construido un azud con dos vanos móviles provistos de compuertas Taintor, y dos aliviaderos laterales.

El rendimiento obtenido de $1 \mathrm{~m}^{3} / \mathrm{s}$ constituye una importante mejora en el abastecimiento de aguas a la capital, habida cuenta del reducido plazo de ejecución y la economía de esta obra.

El agua obtenida resulta de inmejorables condiciones a causa del filtrado a que se encuentra sometida, tanto por los acarreos del río como por los drenes de captación.

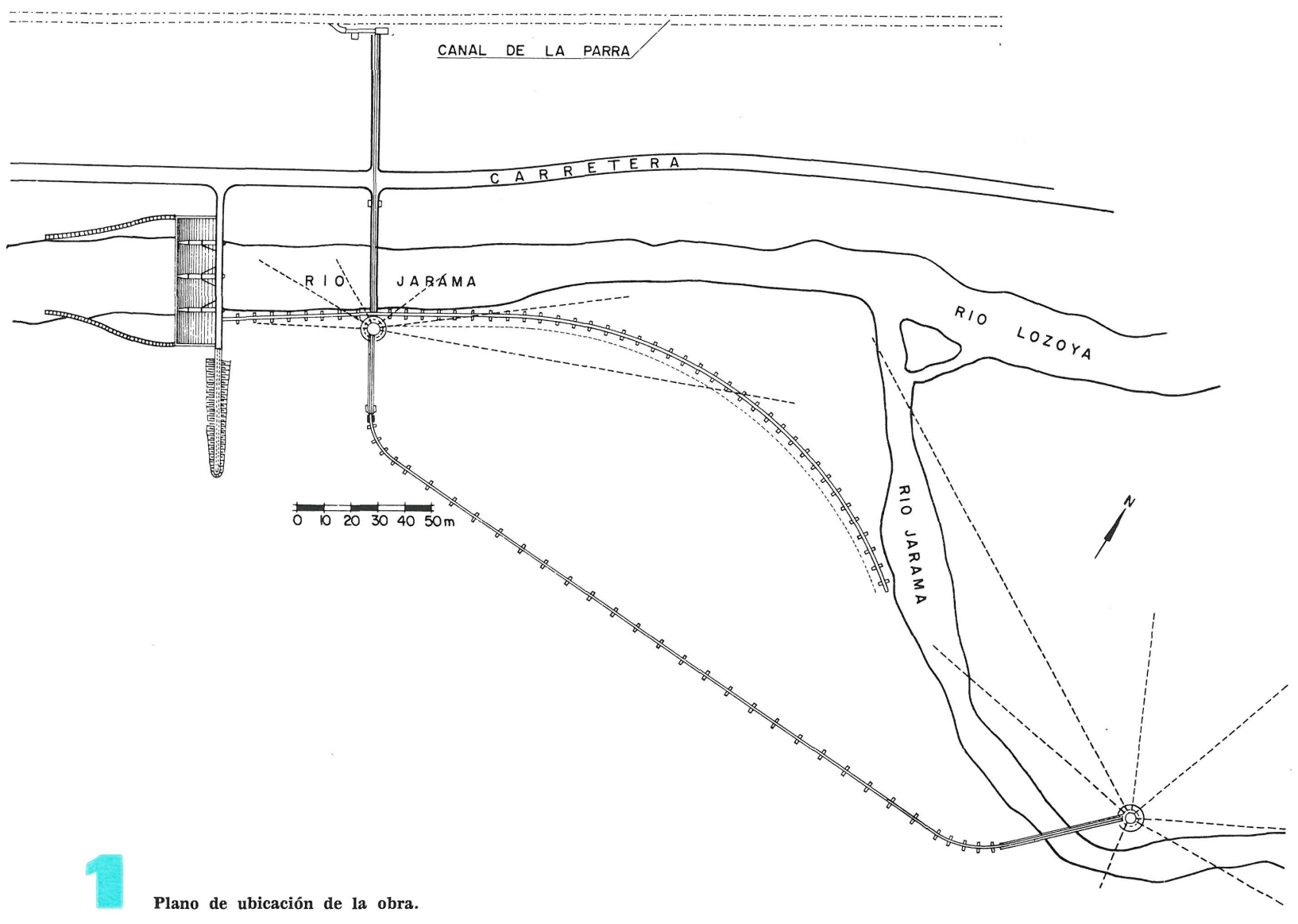




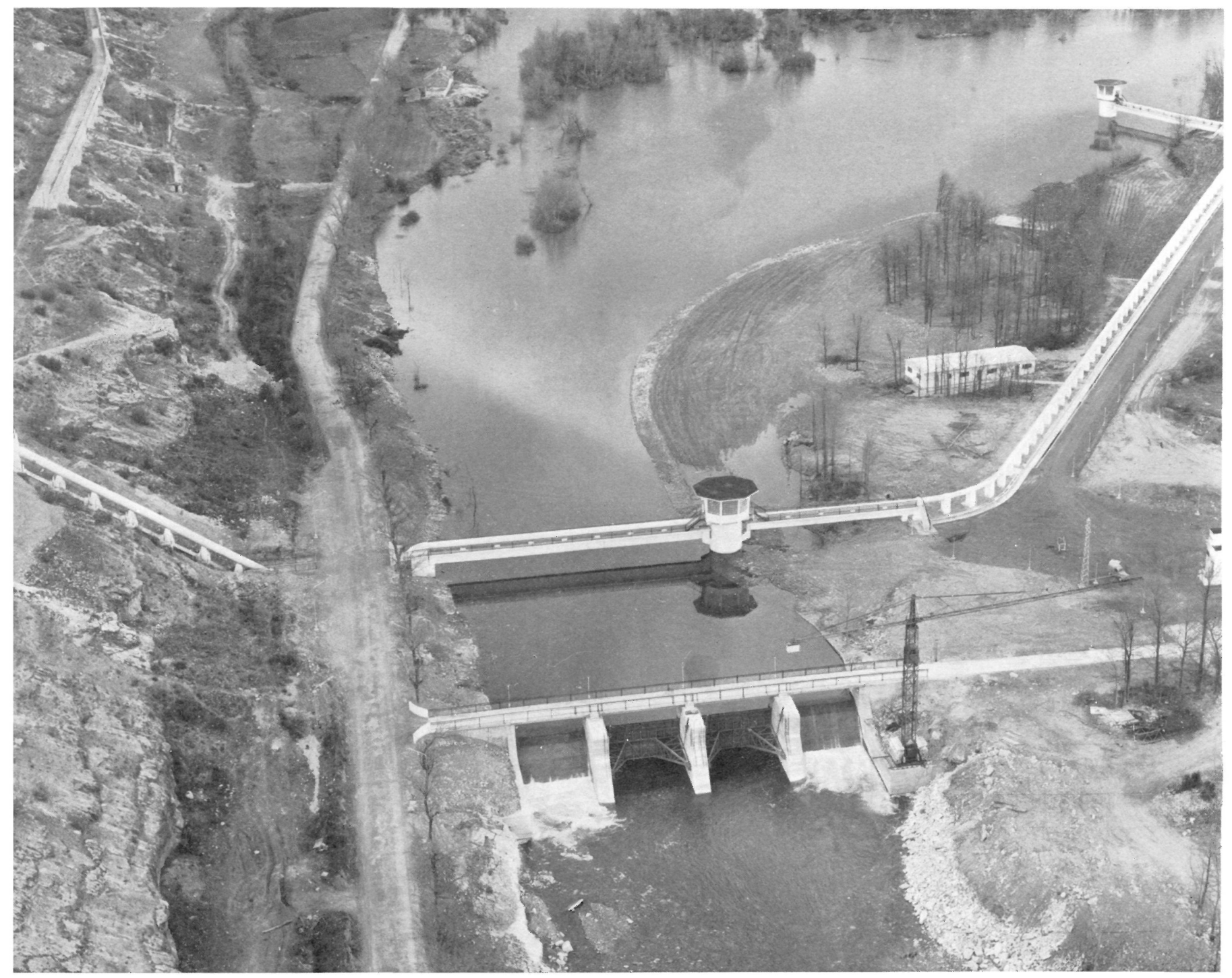

7

Vista del conjunto de las instalaciones de captación (aguas abajo).

\section{Objeto y ubicación de la obra}

El crecimiento incesante de la población de Madrid exige el máximo aprovechamiento de los recursos hidráulicos disponibles.

La forma más generalizada de utilizar estos recursos es derivar las aguas superficiales de los ríos Lozoya, Jarama, Manzanares, etc., a los que se añadirán en breve plazo los caudales procedentes del macizo de Gredos y con posterioridad de los ríos Tiétar, Tormes y Alberche.

No obstante, se ha estudiado la posibilidad de incrementar estos caudales con la captación de aguas subálveas y profundas. Los sondeos practicados en las zonas elegidas permiten determinar el espesor de los acarreos y su permeabilidad, y con estos datos calcular el caudal teórico aprovechable.

La primera captación de este tipo se ha realizado en la confluencia de los ríos Lozoya y Jarama (fig. 1), obteniéndose un caudal de $1 \mathrm{~m}^{3} / \mathrm{s}$, que pasa a reforzar el Canal de La Parra, cuya traza discurre por las inmediaciones de la captación. 


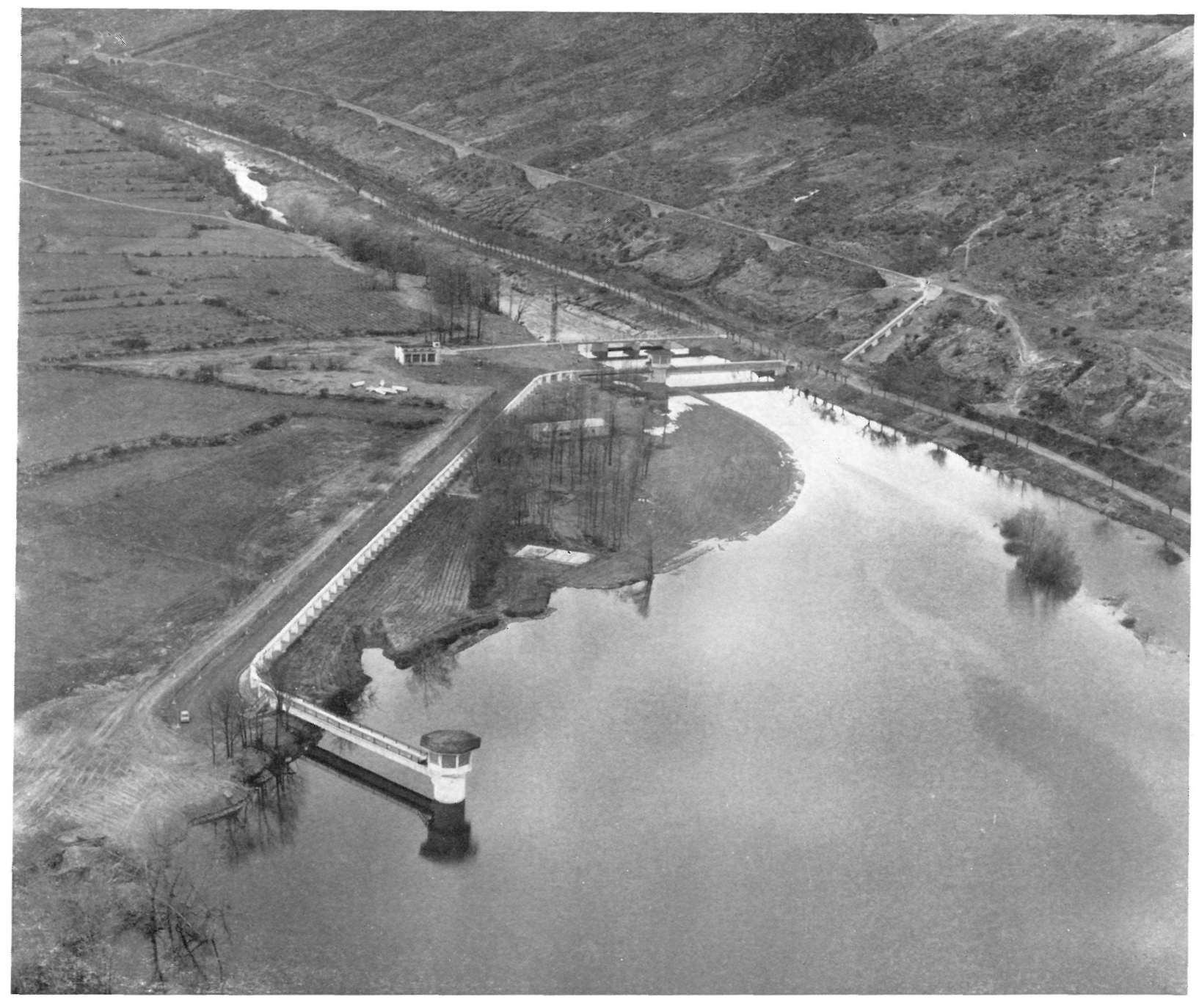

Vista del conjunto de las instalaciones de captación (aguas arriba).

\section{Descripión de las obrass}

Lo esencial de la captación lo forman los pozos Ranney con las instalaciones de impulsión al Canal de La Parra y el azud construido para elevar la carga de agua sobre los drenes (figs. 2 y 3).

\section{Pozos Ranneg}

Se han construido dos, situados en la margen izquierda del río Jarama: uno de ellos, inmediatamente aguas arriba de su confluencia con el río Lozoya, aprovechando una zona de graveras de $4.500 \mathrm{~m}^{2}$, y el otro más aguas abajo, teniendo en cuenta unas conjugadas con las anteriores de 8.400 metros cuadrados.

Para su proyecto se ha tenido en cuenta: A) Estudios geológicos de la zona; B) Estudios geofísicos; C) Ensayos de bombeo en la zona de extensión reducida, donde los sondeos de exploración dieron mejor resultado. 


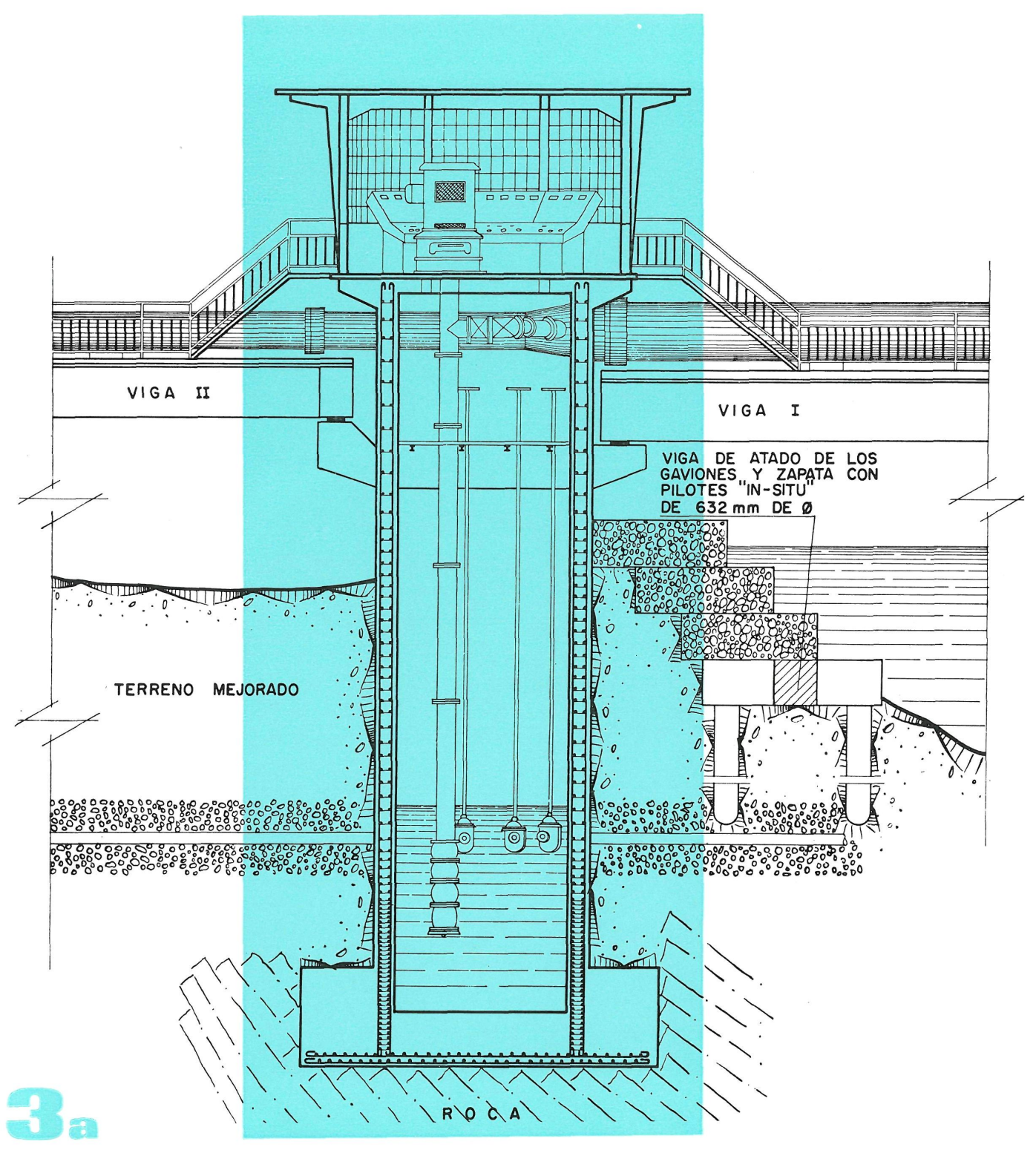

Sección del pozo de captación número uno.

En cuanto al proyecto propiamente dicho, comprende (fig. 3 a):

I. Un cajón cilíndrico de hormigón armado, que constituye el revestimiento del pozo colector central, de $4 \mathrm{~m}$ de diámetro interior y $0,40 \mathrm{~m}$ de espesor; las armaduras, que están calculadas para resistir el empuje del terreno, las tensiones que se produzcan al descolgar el cajón y el empuje de los gatos contra las paredes en la zona de hinca de los drenes, y la parte inferior provista de una cuchilla cortante, de la forma más adecuada, según el terreno a atravesar.

Se prevé asimismo un número determinado de lumbreras por donde se hincaron los drenes, así como un fondo consistente en un tapón sumergido, de hormigón armado, capaz de resistir las subpresiones.

II. Drenes. Se estudia su número y disposición en planta, el diámetro y disposición de las ranuras, la longitud total necesaria para mantener la velocidad adecuada de infiltración, disposición y número de aberturas, según la composición granulométrica de los acarreos.

III. Válvulas y accionamientos.

IV. Plataforma de mandos y escala de bajada al pozo.

V. Superestructura.

VI. Equipos de bombeo eléctricos, de transformación y mandos de motobombas. 

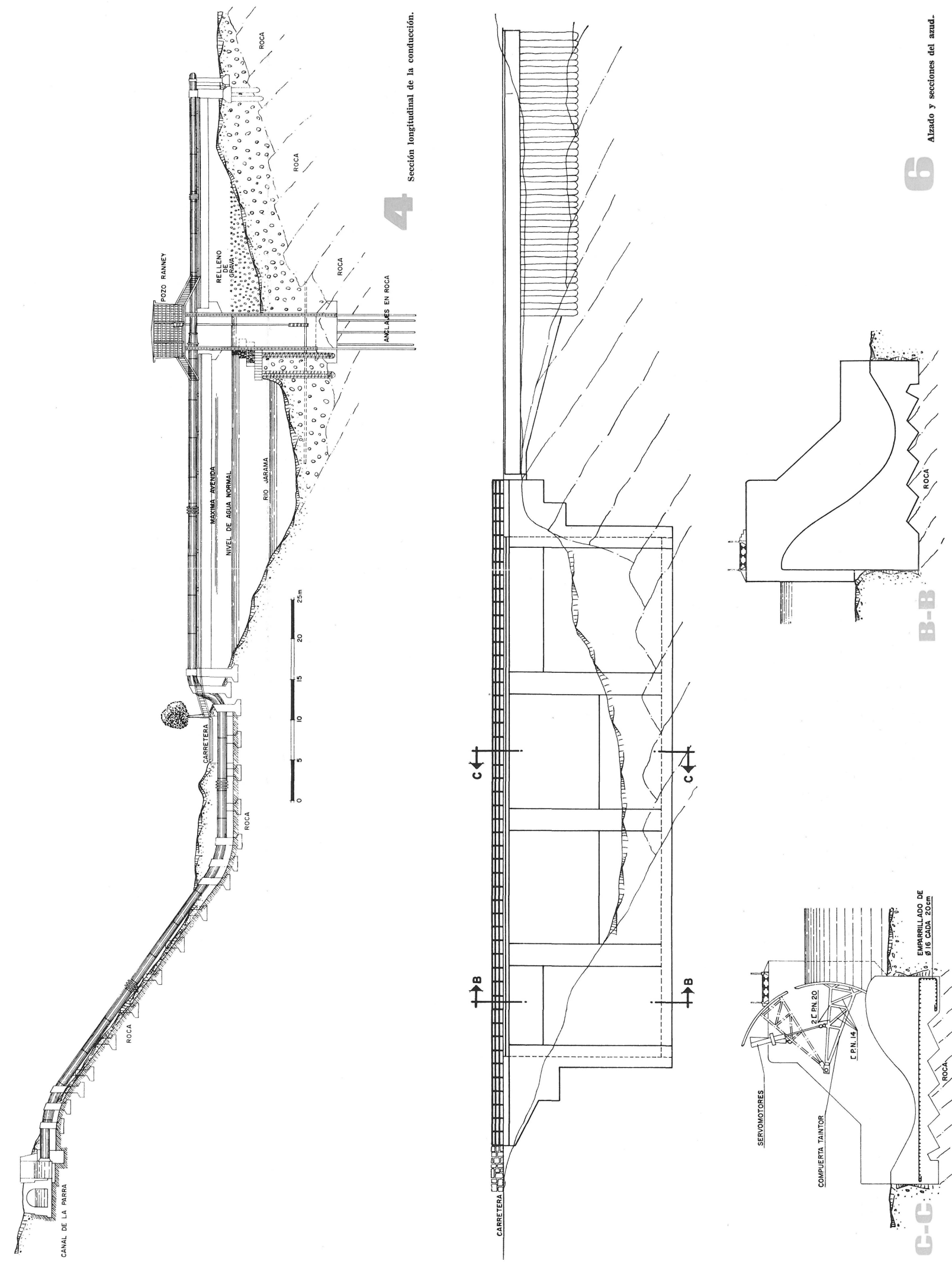


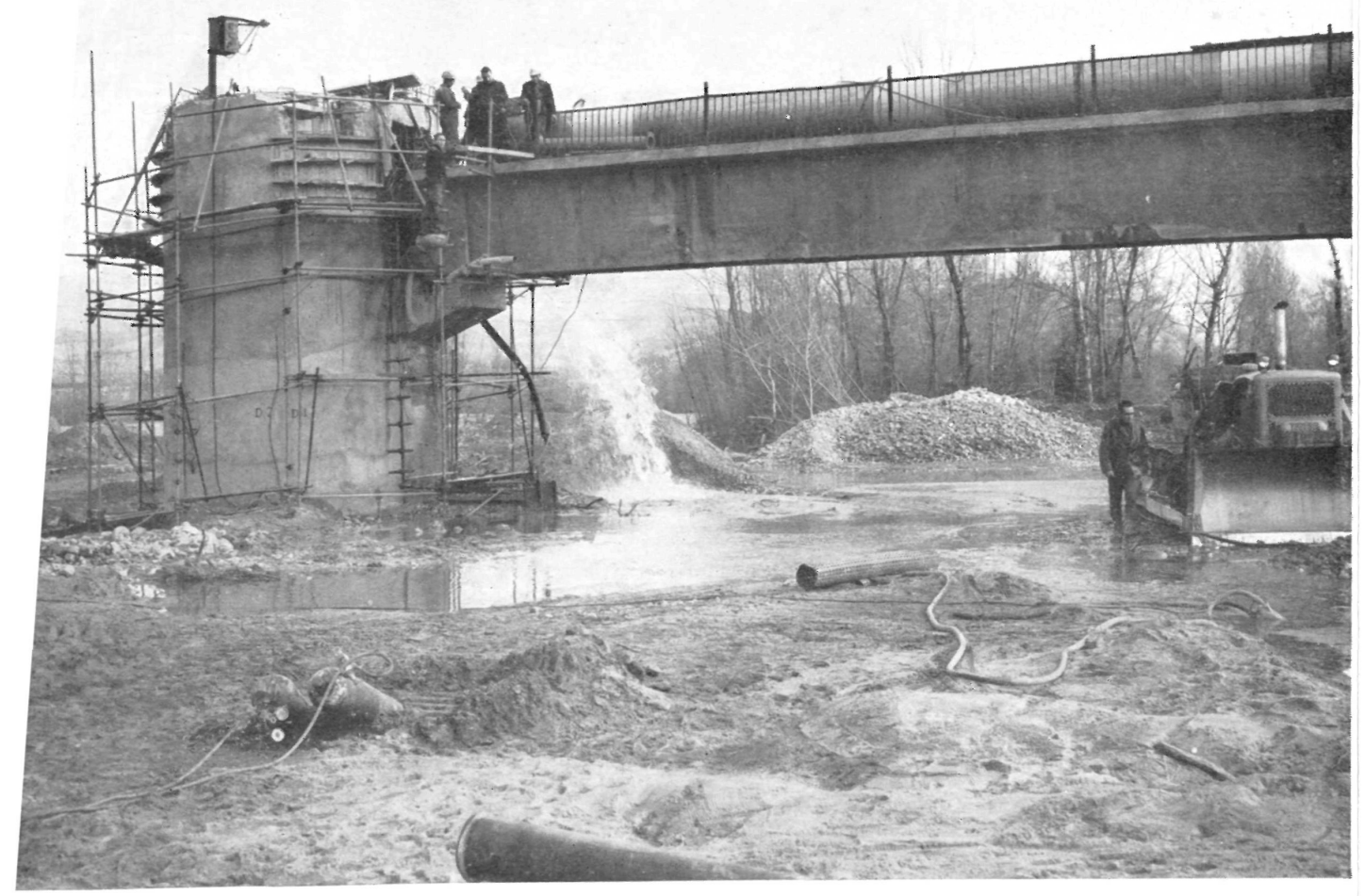

\section{Procedinniemto clásico de comstrucción}

El proceso normal consiste en:

Pozo colector. Se empieza por clavar en el terreno un pozo indio de las características y dimensiones descritas.

Hinca de drenes. Los drenes se van hincando por tramos de $2,5 \mathrm{~m}$, mediante unos gatos especiales de $100 \mathrm{t}$ de potencia cada uno. El primer tramo de cada dren va provisto de una cabeza de avance - «azuche»- agujereada, que puede quedar en comunicación con el interior del pozo por medio de una tubería auxiliar, llamada de desarenado, que se coloca en el interior del dren y concéntrica con él.

La presión hidrostática sobre los agujeros del azuche crea una corriente de agua a gran velocidad por el interior de la tubería de desarenado cuando se abre una válvula en el interior del pozo. Esta corriente da lugar a una intensa succión en los agujeros del azuche, que arrastra elementos finos de la formación capaces de pasar por los orificios y abre camino al avance del dren, al mismo tiempo que perturba la formación, esponjándola. Este efecto de arrastres puede intensificarse alternando las descargas de agua al pozo con inyecciones de aire comprimido a través de un injerto en la tubería de desarenado.

Una vez hincado el primer tramo de $2,5 \mathrm{~m}$, se suelda eléctricamente a su extremo otro de igual longitud, que se hinca de modo análogo, y así se procede sucesivamente hasta llegar a la longitud deseada.

Los drenes tienen una longitud variable, que depende, en cada caso, de las condiciones del acuífero.

Terminada la hinca, se acopla una válvula de compuerta a la pieza que sirvió de guía al dren y que va embebida en el cajón de hormigón por el interior del pozo. 
Desarenado para formar el filtro. La operación de desarenado de la formación a través del dren se realiza acoplando a la tubería auxiliar de desarenado un dispositivo especial, que permite comunicar tramos longitudinales sucesivos, muy cortos $(20$ a $30 \mathrm{~cm})$, del dren, con el interior del pozo. Mediante inyecciones intermitentes de aire comprimido y desaguie al pozo, se establece una pulsación en la corriente de agua que puede circular por la tubería de desarenado, lo que produce un intenso arrastre de los elementos finos.

Terminadas estas operaciones, se montan las válvulas y sus accionamientos; se construye en su caso la superestructura, generalmente apoyada en la prolongación del tubo del pozo sobre la superficie del terreno, a altura suficiente para salvar las máximas avenidas; y se instalan los grupos de bombeo y las instalaciones eléctricas.

\section{Variantes intuoducidas en esta instalkación}

Teniendo en cuenta el pequeño espesor de la capa de acarreos y la granulometría de los mismos, especialmente en el fondo de la formación, donde predominan los bolos de gran tamaño, se decidió variar el proceso clásico de construcción, adoptando la siguiente marcha de las obras:

Pozos colectores. Para cada pozo se creó un recinto estanco por medio de un tablestacado, a fin de construir los cajones de hormigón del revestimiento a cielo abierto. Una vez excavado el interior del recinto, se cimentó y ancló en la roca del fondo el primer anillo de hormigón armado, sellándose con una solera impermeable. Se emplearon encofrados deslizantes.

Drenes. Se realizaron zanjas de $1,50 \mathrm{~m}$ de anchura y profundidad hasta llegar a terreno firme, extendiéndose sobre dichas zanjas una capa de $0,50 \mathrm{~m}$ de espesor de gravas clasificadas y lavadas. Sobre ellas se colocó, por tramos, el dren de $20 \mathrm{~cm}$, soldándose estos tramos unos con otros hasta enlazar con las tuberías del cajón. (En el pozo número 1 se aumentó el diámetro de uno de los drenes a $40 \mathrm{~cm}$.) Los drenes se recubrieron con otra capa de $1,5 \mathrm{~m}$ de gravas clasificadas y lavadas, rellenándose el resto de las zanjas hasta la superficie del terreno con materiales de la formación.

La margen izquierda del río, desde el pozo número 1 hasta unos $200 \mathrm{~m}$ aguas arriba, se protegió con gaviones para establecer el cauce y conseguir con ello una mayor velocidad que mantuviera el fondo limpio. Toda la zona situada detrás de los gaviones se rellenó, asimismo, con materiales de la formación.

El agua filtrada se extrae, con el equipo de bombeo formado en el primer pozo, por dos bombas de eje vertical de rendimiento normal $250 \mathrm{l} / \mathrm{s}$ cada una. El segundo pozo dispone de dos bombas análogas de 500 l/s. El caudal extraído se injerta en el Canal de La Parra por medio de una tubería, de acero laminado electrosoldada, que parte del primer pozo con un diámetro interno de $800 \mathrm{~mm}$ y una capacidad de $500 \mathrm{l} / \mathrm{s}$. Esta tubería atraviesa el segundo pozo, donde se aumenta el diámetro a $1.250 \mathrm{~mm}$, con capacidad para el caudal suministrado por ambos (fig. 4).

Para el acceso del personal a las instalaciones de mandos y controles de bombas, instaladas en la parte superior de los pozos, se han construido unas pasarelas pretensadas, de $42 \mathrm{~m}$ de luz, que a su vez sirven de apoyo a las tuberías (fig. 5). El resto de la conducción discurre a una altura de 2,20 m sobre el terreno.

El injerto en el Canal de La Parra está formado por una arqueta, de hormigón en masa, que sirve como cámara de rotura de carga, de la que parte un canal tranquilizador de sección rectangular. Este canal desemboca en un vertedero en pared delgada con lámina vertiente máxima de 0,70 $\mathrm{m}$ de altura y un caudal de $2 \mathrm{~m}^{3} / \mathrm{s}$. Adosada al canal se ha dispuesto una caseta que aloja el dispositivo de medida de caudales y el telemando para remitir los datos a los filtrantes.

Azud. Está ubicado $50 \mathrm{~m}$ aguas abajo del segundo pozo, coincidiendo con un estrechamiento del cauce, que presenta características óptimas desde el punto de vista topográfico (fig. 6). Su longitud de coronación es de $50 \mathrm{~m}$, y la altura máxima sobre el cimiento, de 14,50 m. En el centro se disponen dos compuertas tipo Taintor, de $10 \times 6 \mathrm{~m}$, accionadas con servomotores con sus mandos alojados en la pila central y con posibilidad de maniobrarse a distancia desde uno de los pozos.

Se disponen dos aliviaderos, contiguos a los vanos centrales, el de la margen derecha de $9 \mathrm{~m}$ de luz. Su capacidad de vertido oscila entre 12,5 y $908 \mathrm{~m}^{3} / \mathrm{s}$, según se trate de regímenes normales o de avenidas, si bien en este segundo caso hay que abrir totalmente las compuertas centrales (fig. $6 \mathrm{a}$ ). Los perfiles de los aliviaderos son tipo Craeger, y el sistema amortiguador del agua en su pie es de lanzamiento sumergido. El terreno en cimentación y estribos está formado por calizas fisuradas en sus primeros metros, que se han impermeabilizado con dos pantallas cortantes de 10 y $5 \mathrm{~m}$ aguas arriba y abajo del azud. 


\section{Obrass arecestomias}

Consisten en una viga de atado de hormigón armado sobre pilotes, en la que se apoya una defensa de gaviones de $3 \mathrm{~m}$ de altura, que llega hasta la cota del embalse. En la zona comprendida entre el trasdós de dichos gaviones y el terreno natural se ha efectuado un relleno de unos $23.000 \mathrm{~m}^{3}$ de acarreos.

El estribo izquierdo del azud se ha prolongado mediante una pantalla continua de pilotes tangentes al tresbolillo. Sobre estos pilotes se apoya una viga, con cabeza de sección en $\mathrm{T}$, que sirve de prolongación a la pasarela que discurre sobre el azud.

Para poder pasar con la tubería de impulsión al Canal de La Parra por debajo de la carretera de Torrelaguna a Valdepeñas de la Sierra se ha ejecutado una losa de hormigón armado.

Completan esta obra la instalación eléctrica complementaria y diferentes detalles constructivos, como accesos, escaleras, zonas ajardinadas.

La terminación de las instalaciones descritas ha sido de gran interés para el abastecimiento de Madrid, sobre todo teniendo en cuenta su relativa economía y rapidez de ejecución, pues de esta forma se dispone de un caudal mínimo de $1 \mathrm{~m}^{3} / \mathrm{s}$, que, como hemos visto, se incorpora al Canal de La Parra.

En cuanto al agua captada, debido a su filtraje bacteriológico realizado por los acarreos superiores del río, queda en condiciones de ser utilizada en el consumo de la capital.

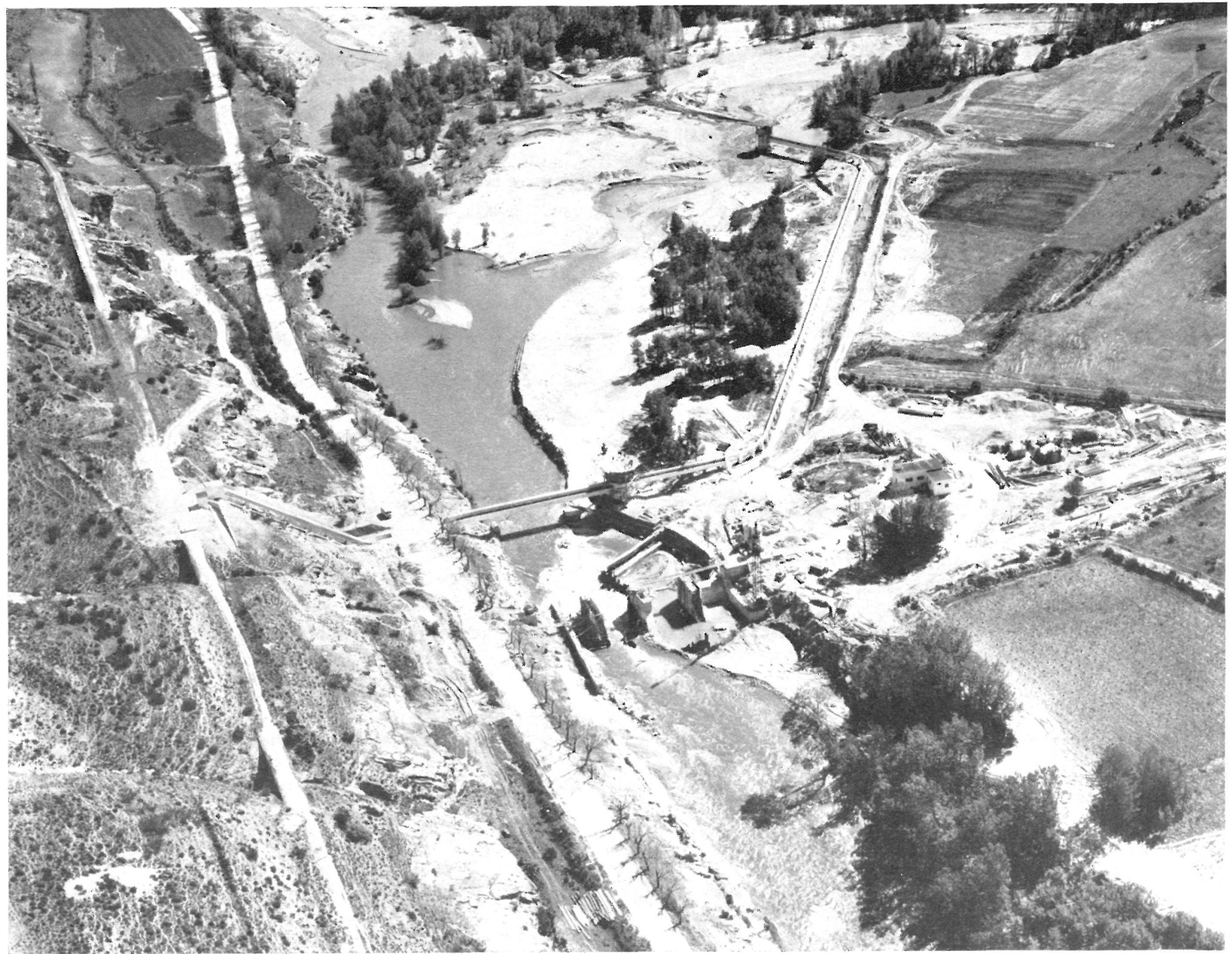




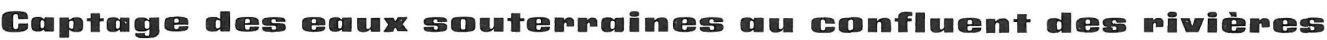 Lożgy Et Darame}

Emilio López de Berges y de los Santos, Dr. ingénieur des Ponts et Chaussées

Le dispositif décrit ici a pour objet de capter le cours souterrain du confluent des rivières Lozoya et Jarama pour l'incorporer au ravitaillement en eau de Madrid.

Le captage se réalise à l'aide de deux puits Ranney à drains radiaux en plaque de tôle rainurée longitudinalement. Chaque puits a une longueur totale d'environ $500 \mathrm{~m}$.

L'eau filtrée est amenée au Canal de La Parra par un conduit en acier soudé à l'électricité de $1 \mathrm{~m}^{3} / \mathrm{s}$ de capacité.

Pour augmenter la charge d'eau sur les drains, a été construit un bassin muni de deux pertuis mobiles à deux vannes Taintor et de deux déversoirs latéraux.

Le rendement obtenu de $1 \mathrm{~m}^{3} / \mathrm{s}$ constitue une importante amélioration pour le ravitaillement en eau de la capitale espagnole, compte tenu du court délai d'exécution et de l'économie réalisée dans ces travaux.

L'eau ainsi obtenue est d'une qualité insuperable grâce au filtrage auquel elle est soumise, tant par les alluvions de la rivière que par les drains de captage.

\section{Bollection of undergiound watrem at the jumetion of the

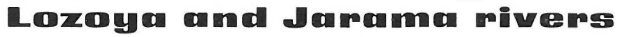

Emilio López de Berges y de los Santos, Dr. civil engineer

The purpose of the arrangement described in this article is to take advantage of the unground water available at the junction of the Lozoya and Jarame rivers, to collect it for the Madrid water supply system.

The water is collected by means of two Ranney wells, with radial drainages in metal plates with longitudinal slits. The total length of these slits, for each well, is $500 \mathrm{~m}$.

The filtered water is pumped to La Parra Canal, along a steel welded tube, with a capacity of $1 \mathrm{~m}^{3} / \mathrm{sec}$.

To increase the water pressure on the drainage surface, a small reservoir has been constructed, with moveable Taintor sluice gates and with two lateral spillways.

The volume of $1 \mathrm{~m}^{3} / \mathrm{s}$ of additional water is an important increase in the water supply of Madrid, especially taking into account the short time taken to complete this project and its low cost.

The water is of very pure quality, owing to the filtration that it undergoes, both along the river bed and at the collecting wells.

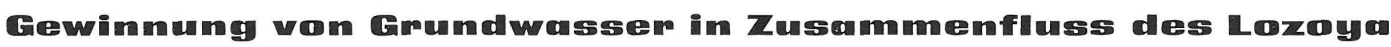 und Jaraman}

Emilio López de Berges y de los Santos, Dr. Bauingenieur

Der Zweck der Anlage, die man beschreibt, ist es die Grundwassermenge des Zusammenflusses des Lozoya und Jarama ver. wenden, um mit Wasser zu Madrid zu versorgen.

Die Gewinnung führt man mit zwei Ranney-Schächte mit radialen Grobblechdräne mit Längennuten und einer Gesamtlänge von $500 \mathrm{~m}$ für jeden Schacht durch.

Das filtrierte Wasser wird zum Kanal «La Parra» durch eine elektrisch geschweisste Stahlleitung mit einer Kapazität von $1 \mathrm{~m}^{3} / \mathrm{s}$. Um die Wassermenge in den Dräne zu vermehren, hat man ein Flusswehr mit zwei beweglichen Wehröffnungen mit TaintorUm die Wassermenge in den Dräne zu vermehren,
Schützen und zwei seitlichen Ueberläufe versehen.

Die Leistungsfähigkeit von $1 \mathrm{~m}^{3} / \mathrm{s}$ stellt eine grosse Verbesserung in der Wasserversorgung nach Madrid dar, da man an der wenig Zeit und Oekonomie der Bauausführung denken muss.

Das Wasser ist sehr gut wegen des Filtrierens, sowohl durch die Geschiebeführung als auch durch die Gewinnungsdräne. 